BMJ Open

Diabetes

Research

\& Care

\title{
Real-world risk of hypoglycemia- related hospitalization in Japanese patients with type 2 diabetes using SGLT2 inhibitors: a nationwide cohort study
}

\author{
Takeshi Horii (D) , ${ }^{1}$ Yoichi Oikawa, ${ }^{2}$ Narumi Kunisada, ${ }^{1}$ Akira Shimada (D) , \\ Koichiro Atsuda ${ }^{1}$
}

To cite: Horii T, Oikawa Y, Kunisada N, et al. Real-world risk of hypoglycemia-related hospitalization in Japanese patients with type 2 diabetes using SGLT2 inhibitors: a nationwide cohort study. BMJ Open Diab Res Care 2020;8:e001856. doi:10.1136/ bmjdrc-2020-001856

- Supplemental material is published online only. To view please visit the journal online (http://dx.doi.org/10.1136/ bmjdrc-2020-001856).

Received 25 August 2020 Revised 14 October 2020 Accepted 4 November 2020

\section{Check for updates}

(C) Author(s) (or their employer(s)) 2020. Re-use permitted under CC BY-NC. No commercial re-use. See rights and permissions. Published by BMJ.

${ }^{1}$ Pharmacy Practice and Science I, Research and Education Center for Clinical Pharmacy, Kitasato University School of Pharmacy, Kanagawa, Japan

${ }^{2}$ Department of Endocrinology and Diabetes, School of Medicine, Saitama Medical University, Iruma-gun, Saitama, Japan

Correspondence to

Takeshi Horii;

horiit@pharm.kitasato-u.ac.jp

\section{ABSTRACT}

Introduction Sodium-glucose cotransporter 2 (SGLT2) inhibitors are believed to lower glucose levels and inhibit cardiovascular events related to type 2 diabetes (T2D). To maximize their benefits, the risk of resultant hypoglycemia has to be minimized; however, the magnitude of this risk remains unclear. Here, we aimed to identify clinical factors linked to an increased risk of hypoglycemia among Japanese patients with T2D and treated with SGLT2 inhibitors.

Research design and methods This was a real-world retrospective cohort study conducted using the Japanese Medical Data Vision database. We identified patients with T2D and treated with SGLT2 inhibitors who were enrolled in the database from April 2014 to October 2019. Cox multivariate regression analyses were performed to determine demographical and clinical factors linked to SGLT2 inhibitor-associated hypoglycemia-related hospitalization.

Results Of 171622 patients prescribed SGLT2 inhibitors, hypoglycemia-related hospitalization occurred in 216 $(0.13 \%)$, with 0.60 incidences per 100 person-years. The risk of SGLT2 inhibitor-associated hypoglycemia was higher with each 10-year increase in age (HR 1.49; 95\% $\mathrm{Cl} 1.32$ to 1.68) and high in patients with body mass index $<25 \mathrm{~kg} / \mathrm{m}^{2}$ (HR 1.98; $95 \% \mathrm{Cl} 1.50$ to 2.61), insulin use (HR 3.26; $95 \% \mathrm{Cl} 2.43$ to 4.38), and sulfonylurea use (HR $1.44 ; 95 \% \mathrm{Cl} 1.02$ to 2.03$)$. The risk was lower in women than in men (HR $0.73 ; 95 \% \mathrm{Cl} 0.54$ to 0.98 ) and low in concomitant metformin users (HR $0.52 ; 95 \% \mathrm{Cl} 0.37$ to 0.74).

Conclusions These findings may help minimize the risk of hypoglycemia-related hospitalization due to T2D treatment with SGLT2 inhibitors. We revealed that the risk of hypoglycemia may be higher when combining SGLT2 inhibitors with sulfonylureas and/or insulin. Furthermore, we discovered a high risk of hypoglycemia in older and non-obese patients. These findings may assist in maximizing the benefits of SGLT2 inhibitors for the treatment of T2D.

\section{INTRODUCTION}

Type 2 diabetes (T2D) is a group of metabolic diseases characterized by a chronic

\section{Significance of this study}

What is already known about this subject?

- The overall risk of hypoglycemia resulting from sodium-glucose cotransporter 2 (SGLT2) inhibitor use is low, and several meta-analyses revealed that the risk of hypoglycemia due to SGLT2 inhibitor monotherapy was similar to that of placebos.

$>$ On the other hand, the Japan Diabetes Society published a recommendation on the proper use of SGLT2 inhibitors, stating that concomitant insulin and/or sulfonylurea use increases the risk of severe hypoglycemia.

What are the new findings?

- In this real-world, retrospective cohort study, we were able to clarify the detailed background of Japanese patients with type 2 diabetes using SGLT2 inhibitors at a high risk of hypoglycemia-related hospitalization.

- In this study, we elucidated the HR of hypoglycemia associated with concomitant sulfonylurea and/or insulin use.

- We were able to clarify other factors that were associated with a higher risk of hypoglycemia, such as a body mass index $<25 \mathrm{~kg} / \mathrm{m}^{2}$ and ageing.

How might these results change the focus of research or clinical practice?

- By considering the comorbidities of individual patients and clarifying the risk of hypoglycemia-related hospitalization under various conditions, the risk of hypoglycemia may be minimized when administering SGLT2 inhibitors.

hyperglycemic state due to insufficient insulin action. Persistent hyperglycemia causes microvascular disorders peculiar to diabetes, such as neuropathy, retinopathy, and renal disorder, as well as large vascular disorders, such as myocardial and cerebral infarction. In Japan, the goal when treating 
T2D is to achieve good glycemic control; to do this, clinicians have two types of injectable hypoglycemic drugs and seven types of oral hypoglycemic drugs at their disposal. Among the latter are sodium-glucose cotransporter 2 (SGLT2) inhibitors, which appeared on the market in 2014. SGLT2 inhibitors have a unique mechanism of action among hypoglycemic drugs, lowering the blood glucose level by inhibiting SGLT2 in the kidneys, which prevents reabsorption of urinary glucose and promotes glucose excretion. ${ }^{1}$ Of further note, in large-scale clinical trials it was reported that these drugs also lowered the risk of cardiovascular events and/or the related hospitalization and mortality rate, ${ }^{2-4}$ as well as lowering the rate of decline in renal function. ${ }^{5-7}$

Despite these beneficial effects, SGLT2 inhibitors pose a risk of hypoglycemia, in those taking certain concomitant medications and in specific patient situations; hypoglycemia is a common side effect of hypoglycemic drugs. Hypoglycemia has been reported to be associated with an increased risk of mortality; therefore, the risk should be minimized. ${ }^{8-10}$ The goal in treating T2D is to achieve good glycemic control in the absence of hypoglycemic events, and iatrogenic hypoglycemia may necessitate a higher glycemic goal than is desirable for patients with T2D. ${ }^{11}$ 12 Other notable risks of hypoglycemia include a reduced health-related quality of life, ${ }^{13}$ reduced work productivity, ${ }^{14}$ and an increased risk of hospitalization due to falls and car accidents. ${ }^{15}$ The American Diabetes Association and the European Association for the Study of Diabetes currently position SGLT2 inhibitors as the center of management of patients with T2D, and it is particularly recommended as first-line treatment for patients with established atherosclerotic cardiovascular disease, heart failure, or chronic kidney disease ${ }^{16}$ SGLT2 inhibitors are a relatively new class of drugs and need to be further evaluated for their safety and tolerability in clinical practice. Since T2D manifests as various pathological conditions, it is necessary to individualize treatment based on the patient's risk of hypoglycemia. The purpose of this study was to identify clinical factors, such as those associated with patient backgrounds and concomitant medications, linked to a higher risk of hypoglycemia among patients with T2D treated with SGLT2 inhibitors.

\section{METHODS}

This was a real-world, retrospective cohort study using data from the Medical Data Vision (MDV) administrative claims database (Medical Data Vision; Tokyo, Japan). It is a nationwide hospital-based claims database covering almost 31 million cumulative patients since April 2008 who, as of October 2019, had been treated as inpatients or outpatients at the approximately 360 hospitals in Japan (21\% of the total number of hospitals) that participate in the diagnosis procedure combination (DPC)/per diem payment system. Of these patients, approximately 3 million ( 10\%) were diagnosed with diabetes mellitus (DM). The MDV database contains anonymized information about patient characteristics, diagnoses, medical expenses, medical procedures, and drug prescriptions. All patient data are encrypted before entry into the database. In this study, we extracted data of administrative claims made from 1 April 2014 to 31 October 2019. We censored patients at the time when they discontinued SGLT2 inhibitors, developed hypoglycemia, lost insurance coverage, or died. For patients prescribed SGLT2 inhibitors, the observation start date was set as the date of first prescription.

\section{Study population}

First, we extracted data of patients diagnosed with DM (International Classification of Diseases, 10th Revision (ICD-10) codes: E10-E14) and registered from 1 April 2008 to 31 October 2019 in the MDV database. We applied the following exclusion criteria to the extracted data set: (1) patients diagnosed with type 1 diabetes (T1D; ICD-10 code: E10); (2) those diagnosed with both T1D and T2D; (3) those diagnosed with any other DM except for T1D and T2D; (4) those aged $<18$ years; and (5) those not prescribed SGLT2 inhibitors. Patients were required to be enrolled in the MDV database for a continuous period of $\geq 6$ months before the observation start date.

\section{Identification of hypoglycemia}

Hypoglycemic events were identified based on previous definitions. ${ }^{17} 18$ We identified hospitalizations for hypoglycemia in the MDV database using the following ICD-9 codes: 251.0 (hypoglycemic coma), 251.1 (other specified hypoglycemia), and 251.2 (hypoglycemia, unspecified). Additionally, the following ICD-10 codes were used: E08.641, E11.641, E11.649, E13.64, E13.641, E13.649, E16.0, E16.1, E15, and E16.2. We excluded patients who did not receive a $50 \%$ glucose injection on the day of admission. We defined hospitalization due to hypoglycemia that met the above conditions as 'hypoglycemia'.

\section{Patient characteristics}

Age, gender, and body mass index (BMI) were included as baseline characteristics and identified using data provided in the claim record in the same month as the observation start date. Obesity was defined as having a BMI $\geq 25 \mathrm{~kg} / \mathrm{m}^{2} .{ }^{19}$ Glycohemoglobin $(\mathrm{HbAlc})$ and estimated glomerular filtration rate (eGFR) were used only as supplementary data. To evaluate eGFR, the creatine level was used. The formula used to calculate eGFR was the following: for males, eGFRcreat $=194 \times$ Cr-1.094 $\times$ age -0.287 , and for females, eGFRcreat $=194 \times$ Cr- $1.094 \times$ age $-0.287 \times 0.739$. As described in a previous study on polypharmacy, ${ }^{20}$ we defined polypharmacy as the use of $\geq 5$ antidiabetic medications.

\section{Statistical analysis}

Patient data following a normal distribution (age, BMI, $\mathrm{HbA1c}$, and eGFR) are expressed as mean $\pm \mathrm{SD}$ values. 


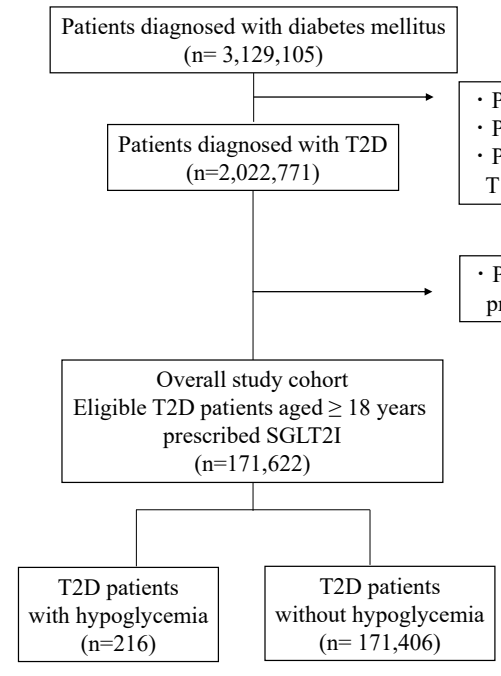

Figure 1 Flow chart of patient inclusion and exclusion. SGLT2I, sodium-glucose cotransporter 2 inhibitor; T1D, type 1 diabetes; T2D, type 2 diabetes.

Continuous variables were analyzed using a one-tailed unpaired t-test. Categorical variables were analyzed using a $\chi^{2}$ test and were expressed as absolute numbers and/or percentages. HRs for the risk of occurrence of hypoglycemia were analyzed using a Cox proportional hazards model, adjusted for types of SGLT2 inhibitors, the administration of antidiabetes drugs other than SGLT2 inhibitors (yes/no), sex, age (10-year increase), and BMI (cut-off value: $25 \mathrm{~kg}$ / $\mathrm{m}^{2}$ ). In the supplemental analysis, the HbAlc (cut-off value: $7.0 \%$ ) and eGFR (stratified as $<30,30-59$, and $\geq 60 \mathrm{~mL} / \mathrm{min}$ ) values were added. All statistical analyses were performed using IBM SPSS Statistics for Windows V.25.0 (IBM).

\section{RESULTS}

\section{Clinical characteristics}

We identified 171622 patients with T2D who were treated with SGLT2 inhibitors (figure 1) during the study period. Table 1 summarizes the clinical characteristics of the study according to hypoglycemic state. Hypoglycemia was observed in $216(0.13 \%)$ of the patients. Males comprised $70.4 \%$ of all patients with hypoglycemia, and no difference $(\mathrm{p}=0.976)$ was observed in the sex ratio between patients with and without hypoglycemia. The mean age was $69.8 \pm 13.6$ years among patients with hypoglycemia, which was higher $(\mathrm{p}=0.003)$ than in those without. The mean BMI was $25.3 \pm 4.9 \mathrm{~kg} / \mathrm{m}^{2}$ among patients with hypoglycemia, which did not differ $(\mathrm{p}=0.211)$ from that of patients without. The mean number of antidiabetic medications was $3.6 \pm 1.2$ among patients with hypoglycemia, which was higher $(\mathrm{p}=0.027)$ than that observed among those without hypoglycemia. The frequency of use of alpha-glucosidase inhibitor, insulin, and sulfonylurea (SU) drugs in patients with hypoglycemia was significantly higher than that observed for patients without hypoglycemia. Glimepiride accounted for the majority of the SU drugs by component (glimepiride: $86.0 \%$, gliclazide: $9.8 \%$, glyburide: $4.2 \%$ ).

\section{Hypoglycemia risk}

The overall incidence of hypoglycemia among patients with T2D receiving SGLT2 inhibitors was 0.60 (95\% CI 0.45 to 0.81 ) per 100 person-years (table 2). Meanwhile, the age group with the highest incidence rate of hypoglycemia was the $\geq 65$ years group $(0.85$ per 100 person-years; $95 \%$ CI 0.60 to 1.21), and the incidence rate of hypoglycemia was highest among those with a BMI $<25$ (1.04 per 100 person-years; $95 \%$ CI 0.72 to 1.51). As expected, the incidence of hypoglycemia was high in patients receiving SGLT2 inhibitorstinsulin (1.20; 95\% CI 0.80 to 1.88 ) and in those receiving SGLT2 inhibitors+SUs $(0.73 ; 95 \%$ CI 0.39 to 1.40$)$.

Next, we investigated the HR of hypoglycemia among the study sample. As depicted in figure 2, female patients had a low risk of hypoglycemia compared with male patients (HR $0.73 ; 95 \%$ CI 0.54 to 0.98$)$. The HR was higher in older patients (1.49 per 10 years; $95 \%$ CI 1.32 to 1.68 ), and was 1.98 -fold higher in patients with a BMI $<25 \mathrm{~kg} / \mathrm{m}^{2}$ than in those with a BMI $\geq 25 \mathrm{~kg} / \mathrm{m}^{2}$. When looking at concomitant medications, it is noteworthy that insulin users had a very high risk of hypoglycemia (HR 3.26; $95 \%$ CI 2.43 to 4.38$)$. Furthermore, SU users had a high risk (HR 1.44; 95\% CI 1.02 to 2.03) and metformin users had a low risk (HR 0.52; 95\% CI 0.37 to 0.74 ). As shown in online supplemental figure 1 , the HR ratio was calculated by classifying the SGLT2 inhibitors into types; none of the drugs were associated with a significant difference. In addition, we examined the risk of hypoglycemia in patients for whom HbAlc and eGFR test results were available $(\mathrm{n}=16754)$ (online supplemental table 1). As illustrated in online supplemental figure 2, the HR was higher in older patients (1.47 per 10 years; $95 \%$ CI 1.03 to 2.10 ), and was 2.42 fold higher in patients with a BMI $<25 \mathrm{~kg} / \mathrm{m}^{2}$ than in those with a BMI $\geq 25 \mathrm{~kg} / \mathrm{m}^{2}$. The HR was 4.78 -fold 
Table 1 Baseline characteristics of patients with T2D using SGLT2 inhibitors

\begin{tabular}{|c|c|c|c|c|c|c|c|}
\hline & \multicolumn{2}{|c|}{ Overall $(n=171622)$} & \multicolumn{2}{|c|}{ Hypoglycemia (+) (n=216) } & \multicolumn{2}{|c|}{ Hypoglycemia (-) $(n=171406)$} & \multirow[b]{2}{*}{$P$ value } \\
\hline & Mean \pm SD & n (\%) & Mean \pm SD & n (\%) & Mean \pm SD & n (\%) & \\
\hline \multicolumn{8}{|l|}{ Sex } \\
\hline Male & & $112521(65.6)$ & & $152(70.4)$ & & $112369(65.6)$ & 0.976 \\
\hline Female & & $59101(34.4)$ & & $64(29.6)$ & & $59037(34.4)$ & \\
\hline Age (years) & $62.4 \pm 13.5$ & & $69.8 \pm 13.6$ & & $62.4 \pm 13.5$ & & 0.003 \\
\hline \multicolumn{8}{|l|}{ Distribution } \\
\hline$<25$ & & $884(0.5)$ & & $1(0.5)$ & & $883(0.5)$ & $<0.001$ \\
\hline $25-44$ & & $17136(10.0)$ & & $10(4.6)$ & & $17126(10.0)$ & \\
\hline $45-64$ & & $69543(40.5)$ & & $53(24.5)$ & & $69490(40.5)$ & \\
\hline$\geq 65$ & & $84059(49.0)$ & & $152(70.4)$ & & $83907(49.0)$ & \\
\hline $\mathrm{BMI}\left(\mathrm{kg} / \mathrm{m}^{2}\right)$ & $27.1 \pm 5.9$ & & $25.3 \pm 4.9$ & & $27.1 \pm 5.9$ & & 0.211 \\
\hline \multicolumn{8}{|l|}{ Distribution } \\
\hline$<25$ & & $65255(38.0)$ & & $114(52.4)$ & & $65141(38.0)$ & $<0.001$ \\
\hline$\geq 25$ & & $106367(62.0)$ & & $102(47.6)$ & & $106265(62.0)$ & \\
\hline $\begin{array}{l}\text { Antidiabetic medications } \\
\text { (n) }\end{array}$ & $2.8 \pm 1.3$ & & $3.6 \pm 1.2$ & & $2.8 \pm 1.3$ & & \\
\hline \multicolumn{8}{|l|}{ Distribution } \\
\hline$<5$ & & $155338(90.5)$ & & $186(86.1)$ & & $155152(90.5)$ & 0.027 \\
\hline$\geq 5$ & & $16284(9.5)$ & & $30(13.9)$ & & $16254(9.5)$ & \\
\hline \multicolumn{8}{|c|}{ Use of other antidiabetic medications } \\
\hline$\alpha-\mathrm{Gl}$ & & $20283(11.8)$ & & 35 (16.2) & & $20248(11.8)$ & 0.046 \\
\hline DPP-4 inhibitors & & $97717(56.9)$ & & $119(55.1)$ & & $97598(56.9)$ & 0.548 \\
\hline Glinides & & $10290(6.0)$ & & $14(6.5)$ & & $10276(6.0)$ & 0.763 \\
\hline GLP-1 receptor agonists & & $7901(4.6)$ & & $8(3.7)$ & & $7893(4.6)$ & 0.528 \\
\hline Insulin & & 34915 (20.3) & & $97(44.9)$ & & $34818(20.3)$ & $<0.001$ \\
\hline Metformin & & $73083(42.6)$ & & $52(24.1)$ & & $73031(42.6)$ & $<0.001$ \\
\hline Sulfonylureas & & $34903(20.3)$ & & $50(23.1)$ & & $34853(20.3)$ & 0.304 \\
\hline Thiazolidinediones & & $12996(7.6)$ & & $15(6.9)$ & & $12981(7.6)$ & 0.727 \\
\hline
\end{tabular}

$P$ values were calculated for differences between patients with and without hypoglycemic events.

Hypoglycemia (+) denotes patients with hypoglycemic events. Hypoglycemia (-) denotes patients without hypoglycemic events.

BMI, body mass index; DPP-4, dipeptidyl peptidase-4; $\alpha$-Gl, alpha-glucosidase inhibitor; GLP-1, glucagon-like peptide-1; SGLT2, sodium-glucose cotransporter 2; T2D, type 2 diabetes;.

(95\% CI 1.73 to 13.2$)$ higher in patients with an eGFR $<30 \mathrm{~mL} / \mathrm{min}$ than in those with an eGFR $\geq 60 \mathrm{~mL} /$ min. Looking at concomitant drugs, both insulin and SU drugs were still associated with a higher HR in this subset of patients (4.87 and 2.18, respectively); however, the HR when using metformin was not statistically significant in this subset.

\section{Duration from initiation of treatment to onset of hypoglycemia}

Finally, we investigated the duration from initiation of treatment with SGLT2 inhibitors until the onset of hypoglycemia in the subset of patients with hypoglycemia; the mean duration was $176.2 \pm 101.0$ days. When dividing hypoglycemia onset into 30-day blocks from initiation of SGLT2 inhibitor treatment, the highest incidence occurred in the first 30 days, with a general downward trend with the passage of time (figure 3 ).

\section{DISCUSSION}

This study revealed a detailed background of Japanese patients with T2D using SGLT2 inhibitors at a high risk of developing hypoglycemia.

SGLT2 inhibitors reduce hyperglycemia by inhibiting proximal tubular reabsorption of glucose in the kidney; thus, the glucose-lowering effect is independent of insulin secretion. ${ }^{1}$ However, SGLT2 inhibitors are unlikely to cause hypoglycemia alone, as indicated previously. (1) Since the glucosuric effect of SGLT2 inhibitors is tied to the filtered load of glucose, they become ineffective once the filtered load reaches $\leq 80 \mathrm{~g} /$ day. ${ }^{21-23}$ (2) SGLT2 inhibitors increase plasma glucagon concentrations and gluconeogenesis in patients with T2D. ${ }^{24}{ }^{25}$ Thus, the risk of hypoglycemia from SGLT2 inhibitors is low; in several meta-analyses of randomized controlled trials (RCTs), the authors reported that the risk of hypoglycemia when SGLT2 
Table 2 Risk of hypoglycemia following initiation of SGLT2 inhibitors

\begin{tabular}{|c|c|c|c|}
\hline & $\mathbf{n}$ & Events & $\begin{array}{l}\text { Events per } 100 \text { person-years } \\
(95 \% \mathrm{Cl})\end{array}$ \\
\hline All patients & 171622 & 216 & $0.60(0.45$ to 0.81$)$ \\
\hline \multicolumn{4}{|l|}{ Sex } \\
\hline Male & 112521 & 152 & 0.66 (0.47 to 0.94$)$ \\
\hline Female & 59101 & 64 & 0.47 (0.28 to 0.84$)$ \\
\hline \multicolumn{4}{|l|}{ Age (years) } \\
\hline$<25$ & 884 & 1 & 0.42 (0.06 to 2.96$)$ \\
\hline $25-44$ & 17136 & 10 & 0.35 (0.10 to 1.29$)$ \\
\hline $45-64$ & 69543 & 53 & 0.38 (0.21 to 0.69$)$ \\
\hline$\geq 65$ & 84059 & 152 & 0.85 (0.60 to 1.21$)$ \\
\hline \multicolumn{4}{|l|}{ BMI $\left(\mathrm{kg} / \mathrm{m}^{2}\right)$} \\
\hline$<25$ & 65255 & 114 & 1.04 (0.72 to 1.51$)$ \\
\hline$\geq 25$ & 106365 & 102 & 0.51 (0.32 to 0.82$)$ \\
\hline \multicolumn{4}{|l|}{ Antidiabetic medications ( $\mathrm{n}$ ) } \\
\hline$<5$ & 155152 & 186 & 0.61 (0.45 to 0.82$)$ \\
\hline$\geq 5$ & 16254 & 30 & 0.21 (0.15 to 0.30$)$ \\
\hline \multicolumn{4}{|c|}{ Baseline use of antidiabetic medications } \\
\hline$\alpha-\mathrm{Gl}$ & 20283 & 35 & 0.69 (0.35 to 1.67$)$ \\
\hline DPP-4 inhibitors & 97717 & 119 & 0.61 (0.41 to 0.91$)$ \\
\hline Glinides & 10290 & 14 & 0.18 (0.15 to 0.23$)$ \\
\hline GLP-1 receptor agonists & 7901 & 8 & 0.19 (0.07 to 0.51$)$ \\
\hline Insulin & 34915 & 97 & 1.20 (0.80 to 1.88$)$ \\
\hline Metformin & 73083 & 52 & 0.31 (0.18 to 0.59$)$ \\
\hline Sulfonylureas & 34903 & 50 & 0.73 (0.39 to 1.40$)$ \\
\hline Thiazolidinediones & 12996 & 15 & 0.18 (0.15 to 0.23$)$ \\
\hline
\end{tabular}

BMI, body mass index; DPP-4, dipeptidyl peptidase-4; $\alpha$-GI, alpha-glucosidase inhibitor; GLP-1, glucagon-like peptide-1; SGLT2, sodium-glucose cotransporter 2 .

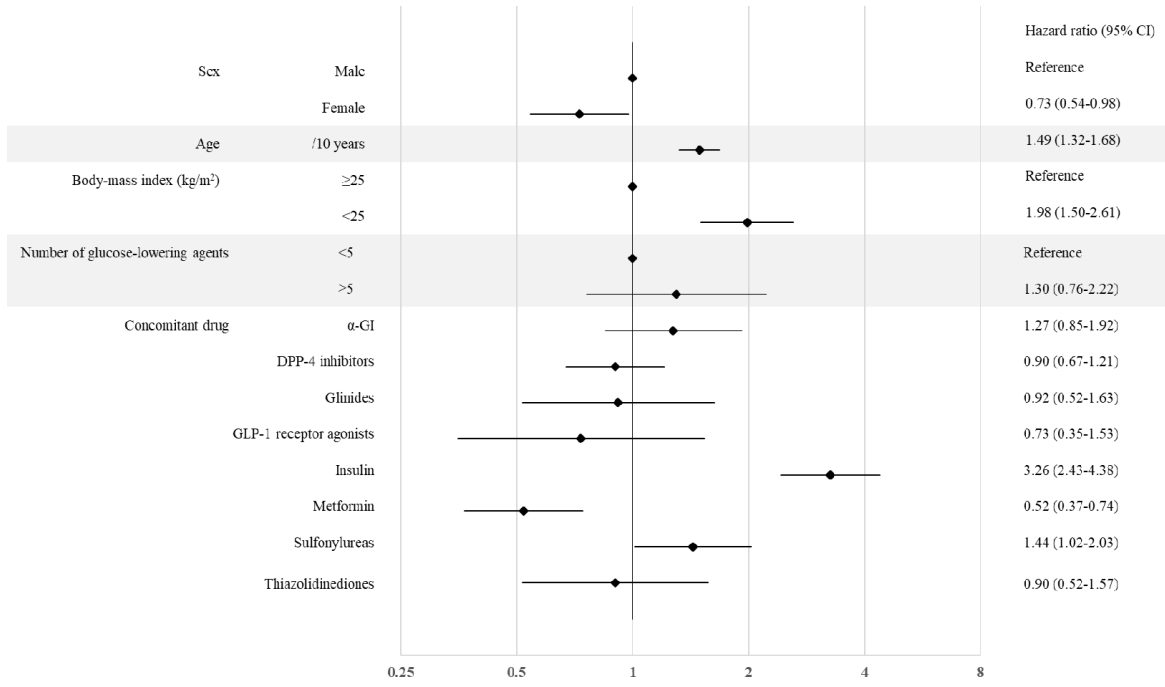

Figure 2 Factors linked to the risk of hypoglycemia in the study sample. The forest plot indicates the HRs (diamonds) and 95\% Cls (horizontal bars) for hypoglycemia among patients with type 2 diabetes using sodium-glucose cotransporter 2 inhibitors, according to baseline characteristics. DPP-4, dipeptidyl peptidase-4; $\alpha-G$, alpha-glucosidase inhibitor; GLP-1, glucagon-like peptide-1. 


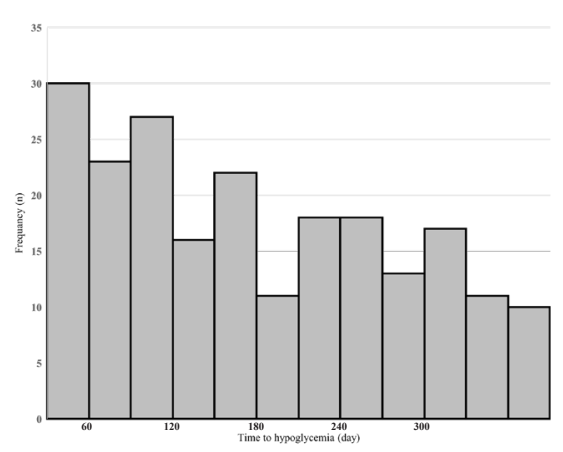

Figure 3 Duration from initiation of treatment with sodiumglucose cotransporter 2 (SGLT2) inhibitor to the onset of hypoglycemia.

inhibitors were used alone was similar or lower to that when placebos were administered. ${ }^{26-28}$ In different RCTs, ${ }^{29-34}$ the incidence rate of hypoglycemia due to SGLT2 inhibitors alone was reported to be $0 \%-36 \%$; in this study, it was at the lower end of that range, at $0.13 \%$. The reason for this may be because of our definition of hypoglycemia as that requiring hospitalization, therefore excluding slight hypoglycemia. On the other hand, the Japan Diabetes Society published a recommendation ${ }^{35}$ on the proper use of SGLT2 inhibitors, stating that its combination with insulin or SUs increases the risk of severe hypoglycemia. One mechanism of action of SGLT2 inhibitors is the loss of body weight, ${ }^{26}$ which, in turn, reduces insulin resistance and enhances the effects of drugs that directly lower blood glucose, such as insulin and SUs. According to a review of safety data by McGill and Subramanian, ${ }^{36}$ when SGLT2 inhibitors were combined with insulin or insulin secretagogues, hypoglycemia was observed in approximately $40 \%$ of patients, similar to what was observed in placebos. Furthermore, Cai $e t a l^{37}$ in their meta-analysis, discovered a similar increase in hypoglycemia risk after treatment with SGLT2 inhibitors when used in combination with insulin or SUs, both in Asian and non-Asian patients. In the present study, the incidence of hypoglycemia on SGLT2 inhibitor treatment in combination with SU and insulin treatment was 0.73 and 1.20 per 100 patient-years, respectively. In addition, the risk of hypoglycemia on SGLT2 inhibitor treatment was 1.46 and 3.40 times higher in combination with SU and insulin use, respectively. Therefore, special attention should be paid to the risk of hypoglycemia when patients use these drugs in combination with SGLT2 inhibitors, as recommended by the Japan Diabetes Society. ${ }^{38}$ Therefore, when prescribing SGLT2 inhibitors, it may be necessary to reduce the prescribed dose of insulin and/or insulin secretagogues. Glimepiride accounted for the majority of the SU drugs targeted in this study. Therefore, we believe that the results of this SU drug mainly reflect the effects of glimepiride.
In our study, a large fraction $(30 / 216,13.9 \%)$ of patients who experienced a hypoglycemic event after initiating SGLT2 inhibitors did so within 30 days. Since the risk seems to decrease over time, the need for carefully managing the risk of hypoglycemia is especially high in the first number of months after initiating SGLT2 inhibitor treatment.

In our study, we discovered that combining metformin treatment with SGLT2 inhibitor treatment resulted in a lower risk of hypoglycemia compared with that observed in patients who are not given metformin therapy. Previous studies ${ }^{39-41}$ reported that such a combination does not carry a high risk for hypoglycemia; however, we are not aware of reports of a lower risk. SGLT2 inhibitors may be a suitable option for obese patients, as metformin alone cannot adequately improve their insulin resistance. As we observed that obese patients were at a lower risk of hypoglycemia on SGLT2 inhibitor usage, its concomitant use with metformin may be a safe option to treat T2D in such patients. The supplementary data provided, which were analyzed by adding HbAlc and eGFR, showed an increase in the HR ratio of hypoglycemia in patients with impaired renal function. Metformin is recommended to be withheld in patients with impaired renal function to avoid adverse events. Therefore, the active administration of metformin to patients who do not have a risk of hypoglycemia due to decreased renal function can be considered as the reason for reducing the risk of hypoglycemia. There are many possible reasons for the lowered risk when SGLT2 inhibitors are combined with metformin therapy; however, these need to be clarified in future studies.

In our study, non-obese patients and those $\geq 65$ years old were discovered to be at greater risk of hypoglycemia than obese and younger patients were. Previous studies have revealed a similar association with BMI and age. Post hoc epidemiological analysis of The Action to Control Cardiovascular Risk in Diabetes (ACCORD) study revealed that a higher BMI was associated with a lower risk of severe hypoglycemia (HR of patients with BMI $\left.\geq 30 \mathrm{~kg} / \mathrm{m}^{2}: 0.65\right),{ }^{42}$ and the Action in Diabetes and Vascular Disease : Preterax and Diamicron Modified Release Controlled Evaluation (ADVANCE) study ${ }^{11}$ revealed a $5 \%$ reduction in the risk of hypoglycemia with each additional $1.0 \mathrm{~kg} / \mathrm{m}^{2}$. A study of Korean patients by Yun $e t a t^{43}$ was also supportive of the above findings. ${ }^{44} 45$ In patients with a low BMI, insulin secretory capacity may be reduced, and insulin and SU drugs may be actively administered; this may be one of the reasons for the increased risk of hypoglycemia. In terms of age, older patients with T2D are more likely to be at risk for severe hypoglycemia-related effects, such as cognitive, renal impairment, and/or polypharmacy. ${ }^{46-48}$

In our study, women had a lower risk of hypoglycemia than men had (HR 0.72; $95 \%$ CI 0.54 to 0.97 ). We are not aware of reports outlining the difference 
in risk of hypoglycemia between men and women. Fluctuations in blood glucose levels depend on a variety of factors, including insulin resistance, insulin secretory capacity, and hepatic glucose control. We speculate that some of these may differ between men and women. In addition, SGLT2 inhibitors have been demonstrated to be involved in improving insulin sensitivity and regulating glucose in the liver. ${ }^{24}$ Since the current study design did not allow us to measure changes in these variables, it was not possible to elucidate the mechanism of the sex differences in hypoglycemia risk. No significant difference was found in the supplemental analysis that corrected for HbA1c or eGFR. The reason may be that the group with decreased eGFR clearly had an increased risk of hypoglycemia, and the gender difference disappeared. In any case, we believe that more patients with HbA1c and eGFR test values need to be collected and analyzed. On analysis of a subset of our study sample, patients with an eGFR $<30 \mathrm{~mL} / \mathrm{min}$ were observed to have a high risk of hypoglycemia (HR 4.78 ; $95 \%$ CI 1.73 to 13.2). On the other hand, in patients with advanced renal dysfunction, hypoglycemia is likely to occur due to decreased gluconeogenesis in the kidneys and decreased insulin clearance. Ito et $a l^{49}$ reported that the admission rate due to hypoglycemia increased with the progression of renal dysfunction. Therefore, attention should be paid to the development of hypoglycemia in patients with renal impairment.

\section{Limitations}

There were several limitations to our study. It is important to recognize that the MDV database does not represent all patients with diabetes in Japan, as it consists only of patients treated in Japanese emergency hospitals that use the DPC system. However, the proportion of patients with T2D in the MDV database $(11 \%)$ is similar to that used in the 2017 Japanese Health and Nutrition Survey (14\%). ${ }^{50}$ This suggests that the MDV data set may be a fair representation of Japanese patients with T2D. As we used the MDV database, it was not possible to track patients, without interruption or gaps, who transferred between hospitals and/or clinics, which may have resulted in the extraction of inaccurate outcomes, such as the inability to identify hypoglycemia. In addition, information on certain confounding factors of hypoglycemia (eg, HbAlc and eGFR) was available in the MDV database only for a limited number of patients. Therefore, future research is needed on large data sets, implementing multivariate hazard models that simultaneously control for multiple potential confounders. Due to the nature of the receipt database, the number of insulin doses could not be investigated; therefore, a detailed study of the insulin regimen was not possible. We believe that assessing the difference in hypoglycemic risk depending on the insulin regimen is necessary for further study.

\section{CONCLUSION}

In conclusion, the present real-world study revealed that patients with T2D and treated with SGLT2 inhibitors have an increased risk of developing hypoglycemia that requires hospitalization when it is combined with insulin or SUs in clinical practice. Furthermore, the risk of hypoglycemia associated with SGLT2 inhibitors was observed to be higher in older and non-obese patients than in those who were younger or obese, respectively. In addition, the risk was lower in female than in male patients, and in those using concomitant metformin. Moreover, our results suggest that a decline in renal function may be involved in the development of hypoglycemia, although it was based on a smaller data set than the other results were. Leveraging these findings may help minimize the risk of severe hypoglycemia due to treatment with SGLT2 inhibitors and may assist in maximizing the benefits of SGLT2 inhibitors for the treatment of T2D.

Acknowledgements The authors thank Associate Professor Nishibata (Kitasato University) and Assistant Professor Wakusugi (Kitasato University) for their assistance in processing large-scale data and completing this survey.

Contributors TH and NK designed the study and analyzed the data. TH wrote the manuscript in consultation with $Y O, K A$ and $A S$. YO, KA and AS reviewed the manuscript and contributed to the discussion. TH is the guarantor of this work and, as such, had full access to all the data in the study, and takes responsibility for the integrity of the data and the accuracy of the data analysis.

Funding The authors have not declared a specific grant for this research from any funding agency in the public, commercial or not-for-profit sectors.

Competing interests AS has received lecture fees from Astellas Pharma, Eli Lilly Japan, Novo Nordisk Pharma, and Sanofi.

Patient consent for publication Not required.

Ethics approval This study was conducted in accordance with ethical guidelines for medical and health research involving human subjects. The ethics board of Kitasato University approved the study (control number: B19-285) and provided permission to review patient records and use the corresponding data. Because all patient data are anonymized for personal data, informed consent was not required for publication.

Provenance and peer review Not commissioned; externally peer reviewed.

Data availability statement Data are available upon reasonable request. All data relevant to the study are included in the article or uploaded as supplemental information. Additional data are available on reasonable request.

Supplemental material This content has been supplied by the author(s). It has not been vetted by BMJ Publishing Group Limited (BMJ) and may not have been peer-reviewed. Any opinions or recommendations discussed are solely those of the author(s) and are not endorsed by BMJ. BMJ disclaims all liability and responsibility arising from any reliance placed on the content. Where the content includes any translated material, BMJ does not warrant the accuracy and reliability of the translations (including but not limited to local regulations, clinical guidelines, terminology, drug names and drug dosages), and is not responsible for any error and/or omissions arising from translation and adaptation or otherwise.

Open access This is an open access article distributed in accordance with the Creative Commons Attribution Non Commercial (CC BY-NC 4.0) license, which permits others to distribute, remix, adapt, build upon this work non-commercially, and license their derivative works on different terms, provided the original work is properly cited, appropriate credit is given, any changes made indicated, and the use is non-commercial. See: http://creativecommons.org/licenses/by-nc/4.0/.

\section{ORCID iDs}

Takeshi Horii http://orcid.org/0000-0002-5465-4531

Akira Shimada http://orcid.org/0000-0002-3954-4983 


\section{REFERENCES}

1 Kashiwagi A, Maegawa $\mathrm{H}$. Metabolic and hemodynamic effects of sodium-dependent glucose cotransporter 2 inhibitors on cardiorenal protection in the treatment of patients with type 2 diabetes mellitus. J Diabetes Investig 2017;8:416-27.

2 Zinman B, Wanner C, Lachin JM, et al. Empagliflozin, cardiovascular outcomes, and mortality in type 2 diabetes. $N$ Engl $J$ Med 2015;373:2117-28.

3 Neal B, Perkovic V, Mahaffey KW, et al. Canagliflozin and cardiovascular and renal events in type 2 diabetes. N Engl J Med 2017;377:644-57.

4 Wiviott SD, Raz I, Bonaca MP, et al. Dapagliflozin and cardiovascular outcomes in type 2 diabetes. N Engl J Med 2019;380:347-57.

5 Perkovic V, de Zeeuw D, Mahaffey KW, et al. Canagliflozin and renal outcomes in type 2 diabetes: results from the canvas program randomised clinical trials. Lancet Diabetes Endocrinol 2018:6:691-704.

6 Perkovic V, Jardine MJ, Neal B, et al. Canagliflozin and renal outcomes in type 2 diabetes and nephropathy. N Engl J Med 2019;380:2295-306.

7 Wanner C, Inzucchi SE, Lachin JM, et al. Empagliflozin and progression of kidney disease in type 2 diabetes. N Engl J Med 2016;375:323-34

8 Bonds DE, Miller ME, Bergenstal RM, et al. The association between symptomatic, severe hypoglycaemia and mortality in type 2 diabetes: retrospective epidemiological analysis of the Accord study. BMJ 2010;340:b4909.

9 McCoy RG, Van Houten HK, Ziegenfuss JY, et al. Increased mortality of patients with diabetes reporting severe hypoglycemia. Diabetes Care 2012;35:1897-901.

10 Zoungas S, Patel A, Chalmers J, et al. Severe hypoglycemia and risks of vascular events and death. $N$ Engl $J$ Med 2010;363:1410-8.

11 Spanakis EK, Cryer PE, Davis SN, et al. Hypoglycemia during therapy of diabetes. In: Feingold KR, Anawalt B, Boyce A, et al, eds. Endotext. South Dartmouth, MA: MDText.com, Inc, 2000. https:// www.ncbi.nlm.nih.gov/sites/books/NBK279100/

12 Cryer PE. The barrier of hypoglycemia in diabetes. Diabetes 2008;57:3169-76.

13 Alvarez-Guisasola F, Yin DD, Nocea G, et al. Association of hypoglycemic symptoms with patients' rating of their healthrelated quality of life state: a cross sectional study. Health Qual Life Outcomes 2010;8:86.

14 Brod M, Christensen T, Thomsen TL, et al. The impact of nonsevere hypoglycemic events on work productivity and diabetes management. Value Health 2011;14:665-71.

15 Signorovitch JE, Macaulay D, Diener M, et al. Hypoglycaemia and accident risk in people with type 2 diabetes mellitus treated with non-insulin antidiabetes drugs. Diabetes Obes Metab 2013;15:335-41.

16 Davies MJ, D'Alessio DA, Fradkin J, et al. Management of hyperglycaemia in type 2 diabetes, 2018. A consensus report by the American diabetes association (ADA) and the European association for the study of diabetes (EASD). Diabetologia 2018;61:2461-98.

17 Whitmer RA, Karter AJ, Yaffe K, et al. Hypoglycemic episodes and risk of dementia in older patients with type 2 diabetes mellitus. JAMA 2009;301:1565-72.

18 Ginde AA, Blanc PG, Lieberman RM, et al. Validation of ICD-9-CM coding algorithm for improved identification of hypoglycemia visits. BMC Endocr Disord 2008;8:4.

19 Examination Committee of Criteria for 'Obesity Disease' in Japan, Japan Society for the Study of Obesity. New criteria for 'obesity disease' in Japan. Circ J 2002;66:987-92.

20 Masnoon N, Shakib S, Kalisch-Ellett L, et al. What is polypharmacy? A systematic review of definitions. BMC Geriatr 2017;17:230.

21 Komoroski B, Vachharajani N, Boulton D, et al. Dapagliflozin, a novel SGLT2 inhibitor, induces dose-dependent glucosuria in healthy subjects. Clin Pharmacol Ther 2009;85:520-6.

22 Heise T, Seewaldt-Becker E, Macha S, et al. Safety, tolerability, pharmacokinetics and pharmacodynamics following 4 weeks' treatment with empagliflozin once daily in patients with type 2 diabetes. Diabetes Obes Metab 2013:15:613-21.

23 Sha S, Devineni D, Ghosh A, et al. Canagliflozin, a novel inhibitor of sodium glucose co-transporter 2 , dose dependently reduces calculated renal threshold for glucose excretion and increases urinary glucose excretion in healthy subjects. Diabetes Obes Metab 2011;13:669-72.

24 Ferrannini E, Muscelli E, Frascerra S, et al. Metabolic response to sodium-glucose cotransporter 2 inhibition in type 2 diabetic patients. J Clin Invest 2014;124:499-508.
25 Merovci A, Solis-Herrera C, Daniele G, et al. Dapagliflozin improves muscle insulin sensitivity but enhances endogenous glucose production. J Clin Invest 2014;124:509-14.

26 Vasilakou D, Karagiannis T, Athanasiadou E, et al. Sodium-Glucose cotransporter 2 inhibitors for type 2 diabetes: a systematic review and meta-analysis. Ann Intern Med 2013;159:262-74.

27 Rådholm K, Wu JH, Wong MG, et al. Effects of sodium-glucose cotransporter-2 inhibitors on cardiovascular disease, death and safety outcomes in type 2 diabetes - a systematic review. Diabetes Res Clin Pract 2018;140:118-28.

28 Zhang L, Zhang M, Lv Q, et al. Efficacy and safety of sodiumglucose cotransporter 2 inhibitors in patients with type 2 diabetes and moderate renal function impairment: a systematic review and meta-analysis. Diabetes Res Clin Pract 2018;140:295-303.

29 Yabe D, Yasui A, Ji L, et al. Safety and tolerability of empagliflozin in East Asian patients with type 2 diabetes: pooled analysis of phase I-III clinical trials. J Diabetes Investig 2019;10:418-28.

30 Ishihara H, Yamaguchi S, Nakao I, et al. Efficacy and safety of ipragliflozin as add-on therapy to insulin in Japanese patients with type 2 diabetes mellitus (IOLITE): a 36-week, open-label extension of a 16-week, randomized, placebo-controlled, double-blind study. Diabetol Int 2019;10:37-50.

31 Inagaki N, Harashima S-I, Maruyama N, et al. Efficacy and safety of canagliflozin in combination with insulin: a double-blind, randomized, placebo-controlled study in Japanese patients with type 2 diabetes mellitus. Cardiovasc Diabetol 2016;15:89.

32 Araki E, Onishi Y, Asano M, et al. Efficacy and safety of dapagliflozin in addition to insulin therapy in Japanese patients with type 2 diabetes: results of the interim analysis of 16-week double-blind treatment period. J Diabetes Investig 2016;7:555-64.

33 Wilding JPH, Woo V, Soler NG, et al. Long-term efficacy of dapagliflozin in patients with type 2 diabetes mellitus receiving high doses of insulin: a randomized trial. Ann Intern Med 2012;156:405-15.

34 Ishihara H, Yamaguchi S, Nakao I, et al. Efficacy and safety of ipragliflozin as add-on therapy to insulin in Japanese patients with type 2 diabetes mellitus (IOLITE): a multi-centre, randomized, placebo-controlled, double-blind study. Diabetes Obes Metab 2016;18:1207-16.

35 Committee on the Proper Use of SGLT2 Inhibitors. Recommendations on the proper use of SGLT2 inhibitors. J Diabetes Investig 2020;11:257-61.

36 McGill JB, Subramanian S. Safety of sodium-glucose co-transporter 2 inhibitors. Am J Med 2019;132:S49-57.

37 Cai X, Gao X, Yang W, et al. No disparity of the efficacy and allcause mortality between Asian and non-Asian type 2 diabetes patients with sodium-glucose cotransporter 2 inhibitors treatment: a meta-analysis. J Diabetes Investig 2018;9:850-61.

38 Namba M, Iwakura T, Nishimura R, et al. The current status of treatment-related severe hypoglycemia in Japanese patients with diabetes mellitus: a report from the Committee on a survey of severe hypoglycemia in the Japan diabetes Society. Diabetol Int 2018;9:84-99.

39 Henry RR, Murray AV, Marmolejo MH, et al. Dapagliflozin, metformin $\mathrm{XR}$, or both: initial pharmacotherapy for type 2 diabetes, a randomised controlled trial. Int J Clin Pract 2012;66:446-56.

40 Hadjadj S, Rosenstock J, Meinicke T, et al. Initial combination of empagliflozin and metformin in patients with type 2 diabetes. Diabetes Care 2016;39:1718-28.

41 Rosenstock J, Chuck L, González-Ortiz M, et al. Initial combination therapy with canagliflozin plus metformin versus each component as monotherapy for drug-naïve type 2 diabetes. Diabetes Care 2016;39:353-62.

42 Miller ME, Bonds DE, Gerstein HC, et al. The effects of baseline characteristics, glycaemia treatment approach, and glycated haemoglobin concentration on the risk of severe hypoglycaemia: post hoc epidemiological analysis of the Accord study. BMJ 2010;340:b5444.

43 Yun J-S, Park Y-M, Han K, et al. Association between BMI and risk of severe hypoglycaemia in type 2 diabetes. Diabetes Metab 2019;45:19-25

44 Butler AE, Janson J, Bonner-Weir S, et al. Beta-cell deficit and increased beta-cell apoptosis in humans with type 2 diabetes. Diabetes 2003;52:102-10.

45 Funakoshi S, Fujimoto S, Hamasaki A, et al. Analysis of factors influencing pancreatic beta-cell function in Japanese patients with type 2 diabetes: association with body mass index and duration of diabetic exposure. Diabetes Res Clin Pract 2008;82:353-8.

46 Yun JS, Ko SH. Risk factors and adverse outcomes of severe hypoglycemia in type 2 diabetes mellitus. Diabetes Metab $J$ 2016:40:423-32. 
47 Kim JT, Oh TJ, Lee YA, et al. Increasing trend in the number of severe hypoglycemia patients in Korea. Diabetes Metab $\mathrm{J}$ 2011;35:166-72.

48 Punthakee Z, Miller ME, Launer LJ, et al. Poor cognitive function and risk of severe hypoglycemia in type 2 diabetes: post hoc epidemiologic analysis of the Accord trial. Diabetes Care 2012;35:787-93.
49 Ito K, Ookawara S, Morishita Y. Hypoglycemic emergency in patients with diabetic kidney disease. Ther Apher Dial 2017;21:512-3.

50 Ministry of Health, Labour and Welfare. National health and nutrition survey (2017), 2017. Available: https://www.mhlw.go.jp/bunya/ kenkou/kenkou_eiyou_chousa.html [Accessed Nov 2019]. 